\title{
Enhanced Natamycin production by Streptomyces natalensis in shake-flasks and stirred tank bioreactor under batch and fed-batch conditions
}

\author{
Elsayed Ahmed Elsayed ${ }^{1,2^{*}}$ (D) Mohamed A. Farid ${ }^{2}$ and Hesham A. El-Enshasy 3,4
}

\begin{abstract}
Background: Natamycin is an antifungal polyene macrolide antibiotic with wide applications in health and food industries. Currently, it is the only antifungal food additive with the GRAS status (Generally Regarded as Safe).

Results: Natamycin production was investigated under the effect of different initial glucose concentrations. Maximal antibiotic production $(1.58 \pm 0.032 \mathrm{~g} / \mathrm{L})$ was achieved at $20 \mathrm{~g} / \mathrm{L}$ glucose. Under glucose limitation, natamycin production was retarded and the produced antibiotic was degraded. Higher glucose concentrations resulted in carbon catabolite repression. Secondly, intermittent feeding of glucose improved natamycin production due to overcoming glucose catabolite regulation, and moreover it was superior to glucose-beef mixture feeding, which overcomes catabolite regulation, but increased cell growth on the expense of natamycin production. Finally, the process was optimized in $7.5 \mathrm{~L}$ stirred tank bioreactor under batch and fed-batch conditions. Continuous glucose feeding for $30 \mathrm{~h}$ increased volumetric natamycin production by about 1.6- and 1.72-folds in than the batch cultivation in bioreactor and shake-flasks, respectively.

Conclusions: Glucose is a crucial substrate that significantly affects the production of natamycin, and its slow feeding is recommended to alleviate the effects of carbon catabolite regulation as well as to prevent product degradation under carbon source limitation. Cultivation in bioreactor under glucose feeding increased maximal volumetric enzyme production by about 72\% from the initial starting conditions.
\end{abstract}

Keywords: Natamycin, Catabolite repression, Degradation, Streptomyces natalensis, Feeding, Bioreactor

\section{Background}

Natamycin is a polyene antibiotic produced by different Streptomyces species in aerobic submerged cultivations. It is also known as pimaricin, tennecetin or natacyn $[1$, 2]. It belongs to the tetraene macrolide antibiotics due to the presence of 4 conjugated double bonds in its lactone ring, which is in turn attached to a mycosamine unit [3, 4]. Major producing strains are S. natalensis, $S$. gilvosporeus, S. chattanogenesis and S. lydicus $[5,6]$. Natamycin exhibits its antimicrobial effect by disrupting

\footnotetext{
* Correspondence: eaelsayed@ksu.edu.sa

'Bioproducts Research Chair, Zoology Department, Faculty of Science, King Saud University, 11451 Riyadh, Kingdom of Saudi Arabia

${ }^{2}$ Chemistry of Natural and Microbial Products Department, National Research Centre, Dokki, Cairo, Egypt

Full list of author information is available at the end of the article
}

the ergosterol content in fungal cell walls, and therefore is characterized by its wide spectrum of antifungal activity against yeast, molds and protozoa [7, 8]. Accordingly, natamycin has found a wide range of applications in the treatment of skin infections, ophthalmic mycoses, oral candidiasis, vaginal candidiasis, bronchopulmonary infections and many systemic fungal infections $[9,10]$. Moreover, natamycin is widely applied in many food industries as a preservative due to its low toxicity to mammalian cells compared to other antimicrobial compounds, and the unlikelihood development of bacterial resistance $[1,11]$. It is considered one of the most important antibiotics added as food preservative approved by the US-FDA and the European Union. Moreover, it is currently the only antifungal food additive with a GRAS (Generally Regarded as Safe) status [12]. It is used in

(c) The Author(s). 2019 Open Access This article is distributed under the terms of the Creative Commons Attribution 4.0 International License (http://creativecommons.org/licenses/by/4.0/), which permits unrestricted use, distribution, and 
many cheese and sausage ripening processes, food packages or coatings due to its inability to diffuse into the product. It is also used to prevent fungal growth in beverages as well as in crop protection [13, 14].

The production of natamycin is usually carried out in submerged cultivations. Different strategies have been used to maximize natamycin production. These include optimization of medium composition and cultivation parameters $[2,5,15,16]$, engineering of the biosynthetic pathway [17], random mutation and selection [18] and genome shuffling and chromosomal integration [19]. Furthermore, addition of short-chain carboxylic or fatty acids has been found to improve natamycin production $[5,20]$. The production process of antibiotics mainly depends on applying batch or fed-batch modes [21-24]. Fed-batch is characterized by feeding one or more of the components of the production medium, usually the limiting components, to avoid problems associated with their depletion from medium. Pathway engineering and genetic manipulation greatly improved natamycin production, where the improved strains produced about about 3.3 and $8.2 \mathrm{~g} / \mathrm{L}$ natamycin in shake-flask and bioreactor levels, respectively $[17,19]$. On the other hand, optimization of medium composition and cultivation parameters in shake-flask level resulted in the production of $1.5-1.6 \mathrm{~g} / \mathrm{L}$ natamycin $[15,16]$. Li et al. [20] were able to produce about $10.38 \mathrm{~g} /$ $\mathrm{L}$ natamycin in shake-flask cultivations with the addition of lower alcohols. On the other hand, combining butanol addition with random mutation resulted in the production of 1.62 and $2.8 \mathrm{~g} / \mathrm{L}$ natamycin in shake-flask and bioreactor levels, respectively [18]. We have previously investigated the effect of addition of short-chain carboxylic acids on the production of natamycin in both shake-flask and bioreactor levels. The optimized cultivation and addition conditions resulted in the production of 3.0 and $3.98 \mathrm{~g} / \mathrm{L}$ natamycin in both cultivation systems, respectively [5].

The production of polyene macrolides is limited by the application of glucose as a carbon source due to its integration in the antibiotic molecule [25]. However, glucose is a fast assimilated C-source and is known to repress the production of many antibiotics due to carbon catabolite regulation [26]. Despite prolonged industrial interest in natamycin, relatively little information has been published regarding production processes under the influence of glucose limitation.

In the present work, the effect of initial glucose concentration on the kinetics of cell growth, glucose consumption and natamycin production was investigated. Moreover, the effect of intermittent feeding of glucose or glucose-beef extract mixture on natamycin production was investigated in shake-flask cultivations. Finally, the process of natamycin production was studied in 7.5 L-stirred tank bioreactor under batch and continuous feeding conditions.

\section{Results}

Effect of initial glucose concentration on kinetics of cell growth and natamycin production in batch cultures These experiments aimed at investigating the effect of different initial glucose concentration on cell growth and production kinetics in shake flask cultivations. The obtained results (Fig. 1, Table 1) clearly showed that initial glucose concentration significantly affected production process parameters $(p=0.001)$. Under all glucose concentrations, cells grew exponentially for the first $40 \mathrm{~h}$, where they reached their maximal cell dry weight. After which, cells entered the stationary phase for the rest of the cultivation time. It can be seen that both maximal cell dry weight and cell growth rates increased proportionally with the initial glucose concentration. At $50 \mathrm{~g} / \mathrm{L}$ glucose, a maximal cell dry weight of $5.66 \pm 0.19 \mathrm{~g} / \mathrm{L}$ was obtained, which was $73.6 \%$ higher than $\mathrm{X}_{\max }$ obtained at $10 \mathrm{~g} / \mathrm{L}$. Furthermore, it can be seen that average cell growth rates at $20,30,40$ and $50 \mathrm{~g} / \mathrm{L}$ increased by about 33.0, 46.7, 60.0 and $88.0 \%$, respectively, than the $\mathrm{Q}_{\mathrm{x}}$ obtained at $10 \mathrm{~g} / \mathrm{L}$. Additionally, the maximal cell dry weights obtained at $30-50 \mathrm{~g} / \mathrm{L}$ recorded comparable values by the end of cultivation (Table 1).

For glucose consumption, results showed that both 10 and $20 \mathrm{~g} / \mathrm{L}$ glucose cultivations were characterized by complete glucose consumption at an average consumption rate of -0.22 and $-0.41 \mathrm{~g} / \mathrm{L} / \mathrm{h}$ after 40 and $80 \mathrm{~h}$, respectively. On the other hand, cultivations supplemented with higher glucose concentration $\left(\mathrm{Q}_{\mathrm{s}}\right)$ did not suffer from glucose depletion, and their average glucose consumption rates increased with increasing glucose concentrations $(-0.44,-0.51$ and $-0.60 \mathrm{~g} / \mathrm{L} / \mathrm{h}$, for 30,40 and $50 \mathrm{~g} / \mathrm{L}$, respectively). By the end of the cultivation time, about 16.7, 29.8 and $29.9 \%$ of the initial glucose remained in the cultivation media supplemented with 30,40 and $50 \mathrm{~g} / \mathrm{L}$ glucose, respectively.

Concerning natamycin production, results showed that natamycin production started at all glucose concentrations after $8 \mathrm{~h}$. At $10 \mathrm{~g} / \mathrm{L}$ glucose, natamycin was produced with an average production rate of $0.011 \mathrm{~g} / \mathrm{L} / \mathrm{h}$ and reached its maximal volumetric production of $0.35 \pm 0.04 \mathrm{~g} / \mathrm{L}$ after 40 h. Increasing glucose concentration to $20 \mathrm{~g} / \mathrm{L}$ has a pronounced effect on natamycin production, where its production rate increased by about $91 \%(0.02 \mathrm{~g} / \mathrm{L} / \mathrm{h})$ and reached a maximal production of $1.58 \pm 0.032 \mathrm{~g} / \mathrm{L}$ after 80 $h$. On the other hand, further increase in glucose concentration $(\geq 30 \mathrm{~g} / \mathrm{L}$ ) adversely affected natamycin production where the maximal volumetric productivity decreased by about $48.1,72.8$ and $72.8 \%$ at 30,40 and $50 \mathrm{~g} / \mathrm{L}$, respectively, from the maximal production at $20 \mathrm{~g} / \mathrm{L}$. Moreover, the average production rate at these cultivations decreased and ranged from 0.006 to $0.013 \mathrm{~g} / \mathrm{L} / \mathrm{h}$. The collective data in Table 1 shows that the growth and production coefficient yields recorded their maximal values at $20 \mathrm{~g} / \mathrm{L}$ 


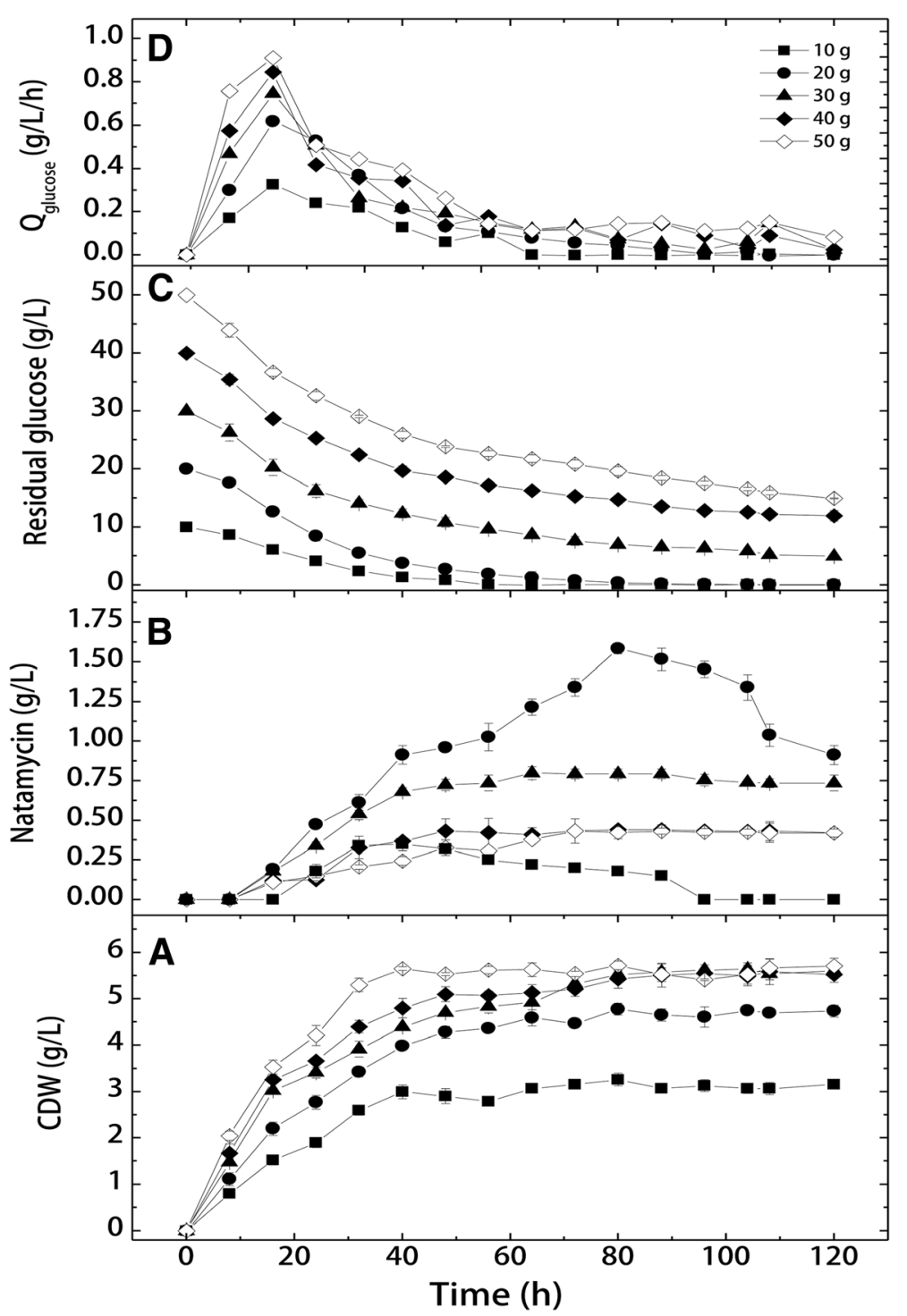

Fig. 1 Effect of different initial glucose concentrations on cell growth and natamycin production by S. natalensis (CDW, cell dry weight; $Q_{\text {glucose, }}$ glucose consumption rate)

Table 1 Kinetic parameters of cell growth and natamycin production by S. natalensis NRRL 2651 as affected by initial glucose concentration

\begin{tabular}{llllllllll}
\hline Concentration $(\mathrm{g} / \mathrm{L})$ & $\mathrm{X}_{\max }(\mathrm{g} / \mathrm{L})$ & $\mathrm{P}_{\max }(\mathrm{g} / \mathrm{L})$ & $\Delta \mathrm{S}(\%)$ & $\mathrm{Q}_{x}{ }^{a}(\mathrm{~g} / \mathrm{L} / \mathrm{h})$ & $\mathrm{Q}_{\mathrm{p}}{ }^{a}(\mathrm{~g} / \mathrm{L} / \mathrm{h})$ & $\mathrm{Q}_{\mathrm{s}}{ }^{\mathrm{a}}(\mathrm{g} / \mathrm{L} / \mathrm{h})$ & $Y_{\mathrm{x} / \mathrm{s}}(\mathrm{g} / \mathrm{g})$ & $Y_{\mathrm{p} / \mathrm{s}}(\mathrm{g} / \mathrm{g})$ & $Y_{\mathrm{p} / \mathrm{x}}(\mathrm{g} / \mathrm{g})$ \\
\hline 10 & $3.26 \pm 0.13$ & $0.35 \pm 0.04$ & 100 & 0.075 & 0.011 & -0.22 & 0.35 & 0.038 & 0.121 \\
20 & $4.78 \pm 0.13$ & $1.58 \pm 0.03$ & 100 & 0.099 & 0.021 & -0.41 & 0.28 & 0.083 & 0.332 \\
30 & $5.66 \pm 0.14$ & $0.82 \pm 0.03$ & 85.8 & 0.11 & 0.013 & -0.39 & 0.39 & 0.044 & 0.185 \\
40 & $5.59 \pm 0.23$ & $0.43 \pm 0.02$ & 72 & 0.12 & 0.006 & -0.38 & 0.31 & 0.027 & 0.122 \\
50 & $5.66 \pm 0.19$ & $0.43 \pm 0.07$ & 70 & 0.14 & 0.006 & -0.50 & 0.31 & 0.015 & 0.102 \\
\hline
\end{tabular}

$\mathrm{X}_{\text {max }}$ : maximal cell dry weight; $\mathrm{P}_{\max }$ : maximal natamycin production; $\Delta \mathrm{S}$ : \% consumed glucose; $\mathrm{Q}_{\mathrm{x}}$ : average cell growth rate; $\mathrm{Q}_{\mathrm{p}}$ : average natamycin production rate; $Q_{S}$ : average glucose consumption rate; $Y_{\mathrm{X} / \mathrm{S}}$ : maximal yield of biomass per consumed glucose; $Y_{\mathrm{P} / \mathrm{s}}$ : maximal yield of natamycin per consumed glucose; $Y_{\mathrm{P} / \mathrm{X} \text { : }}$ maximal yield of natamycin per biomass. ${ }^{a}$ Data are calculated at the end of the exponential growth phase 
glucose. Furthermore, at $20 \mathrm{~g} / \mathrm{L}$, it can be seen that the substrate conversion yield into biomass was the least recorded ( $0.28 \mathrm{~g}$ cells/g consumed glucose), while natamycin yields per consumed glucose and produced cell mass were at their maximal values $(0.083 \mathrm{~g}$ natamycin $/ \mathrm{g}$ consumed glucose, and $0.33 \mathrm{~g}$ natamycin/g cells).

It can be further observed that at 10 and $20 \mathrm{~g} / \mathrm{L}$ glucose the natamycin production decreased gradually with time reaching a minimum of $0.15 \pm 0.02$ and $0.913 \pm 0.06 \mathrm{~g} / \mathrm{L}$ at 88 and $120 \mathrm{~h}$, respectively. Furthermore, in cultivation with $20 \mathrm{~g} / \mathrm{L}$ glucose, natamycin completely disappeared in culture broth after $96 \mathrm{~h}$, in other words, $16 \mathrm{~h}$ after complete glucose consumption. Therefore, the data representing the progress of natamycin production rates at different initial glucose concentrations were summarized in Fig. 2. It can be seen that the production rates increased initially at all glucose concentrations, and then started to slow down. At 10 and 20 $\mathrm{g} / \mathrm{L}$ glucose, natamycin production rates started to decrease after 40 and $80 \mathrm{~h}$ and recorded negative rate values $(-0.0053$ and $-0.0143 \mathrm{~g} / \mathrm{L} / \mathrm{h}$, respectively) indicating that the produced natamycin was degraded in the medium (rates below the base line). On the other hand, at higher glucose concentrations, natamycin production rates decreased and were almost around the zero level $(-0.0012,-0.0004$ and $0.0007 \mathrm{~g} / \mathrm{L} / \mathrm{h}$ at 30,40 and $50 \mathrm{~g} / \mathrm{L}$, respectively), meaning that natamycin production was stopped. In such case, the produced natamycin still can be determined in the production medium at all three concentrations $(30-50 \mathrm{~g} / \mathrm{L})$.
Effect of intermittent feeding of glucose-beef extract mixture on cell growth and natamycin production by $S$. natalensis in shake flasks

During these cultivations, a sterile feeding solution containing glucose and beef extract was fed to the growing cells at the same initial C:N ratio (before glucose depletion). Feeding started after $48 \mathrm{~h}$ of cultivation and was repeated every $24 \mathrm{~h}$ for 5 repeated batches. Obtained results (Fig. 3) showed that cells grew exponentially for the first $48 \mathrm{~h}$ with an average growth rate of $0.08 \mathrm{~g} / \mathrm{L} / \mathrm{h}$, reaching $3.86 \pm 0.021 \mathrm{~g} / \mathrm{L}$, and consumed glucose at an average consumption rate of $-0.27 \mathrm{~g} / \mathrm{L} / \mathrm{h}$. Upon intermittent addition, cells continued to grow almost with the same growth rate $(0.07 \mathrm{~g} / \mathrm{L} / \mathrm{h})$ and reached a maximal cell growth of $12.25 \pm 0.45 \mathrm{~g} / \mathrm{L}$ at $168 \mathrm{~h}$. However, during intermittent feeding of glucose-beef extract mixture, the average glucose consumption rate was increased by about 1.15 -folds $(-0.311 \mathrm{~g} / \mathrm{L} / \mathrm{h})$. Consequently, glucose started to accumulate in the production medium with each feeding batch, where a final residual concentration of $19.6 \pm$ $1.27 \mathrm{~g} / \mathrm{L}$ of glucose was found by the end of the cultivation (39\% of the total added glucose).

For natamycin production, it can be seen that during the first normal batch $(48 \mathrm{~h})$, natamycin was produced by a normal batch production rate of $0.022 \mathrm{~g} / \mathrm{L} / \mathrm{h}$, where volumetric production reached $1.057 \pm 0.09 \mathrm{~g} / \mathrm{L}$. However, after the first feeding batch (at $72 \mathrm{~h}$ ), natamycin concentration recorded $1.61 \pm 0.02 \mathrm{~g} / \mathrm{L}$, a $20 \%$ increment from the $1.34 \pm 0.05 \mathrm{~g} / \mathrm{L} \mathrm{ob}-$ tained in normal batch cultivation after $72 \mathrm{~h}$ (Fig. 1). After the 2nd feeding batch (at $96 \mathrm{~h}$ ), natamycin concentration reached $1.709 \pm 0.009 \mathrm{~g} / \mathrm{L}$, which corresponds to $17.5 \%$ increase from its corresponding batch value $(1.454 \pm 0.05 \mathrm{~g} / \mathrm{L}$

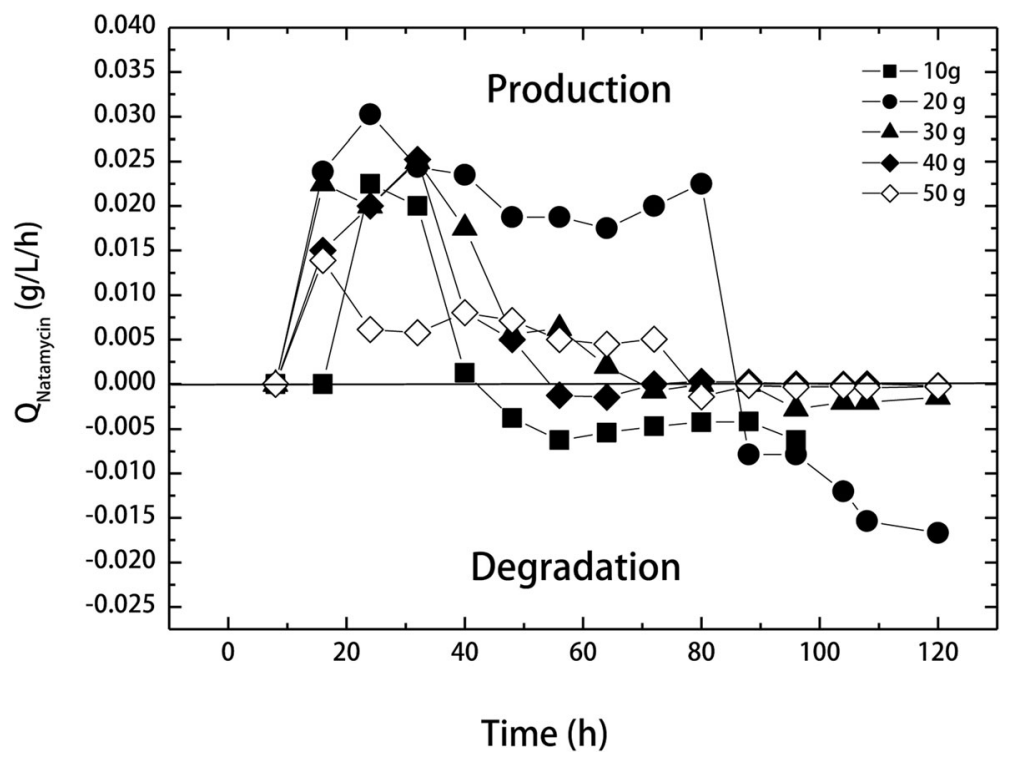

Fig. 2 Production and degradation rates of natamycin in batch culture as affected by different initial glucose concentrations $\left(Q_{\text {natamyccin }}\right.$ natamycin production rate) 


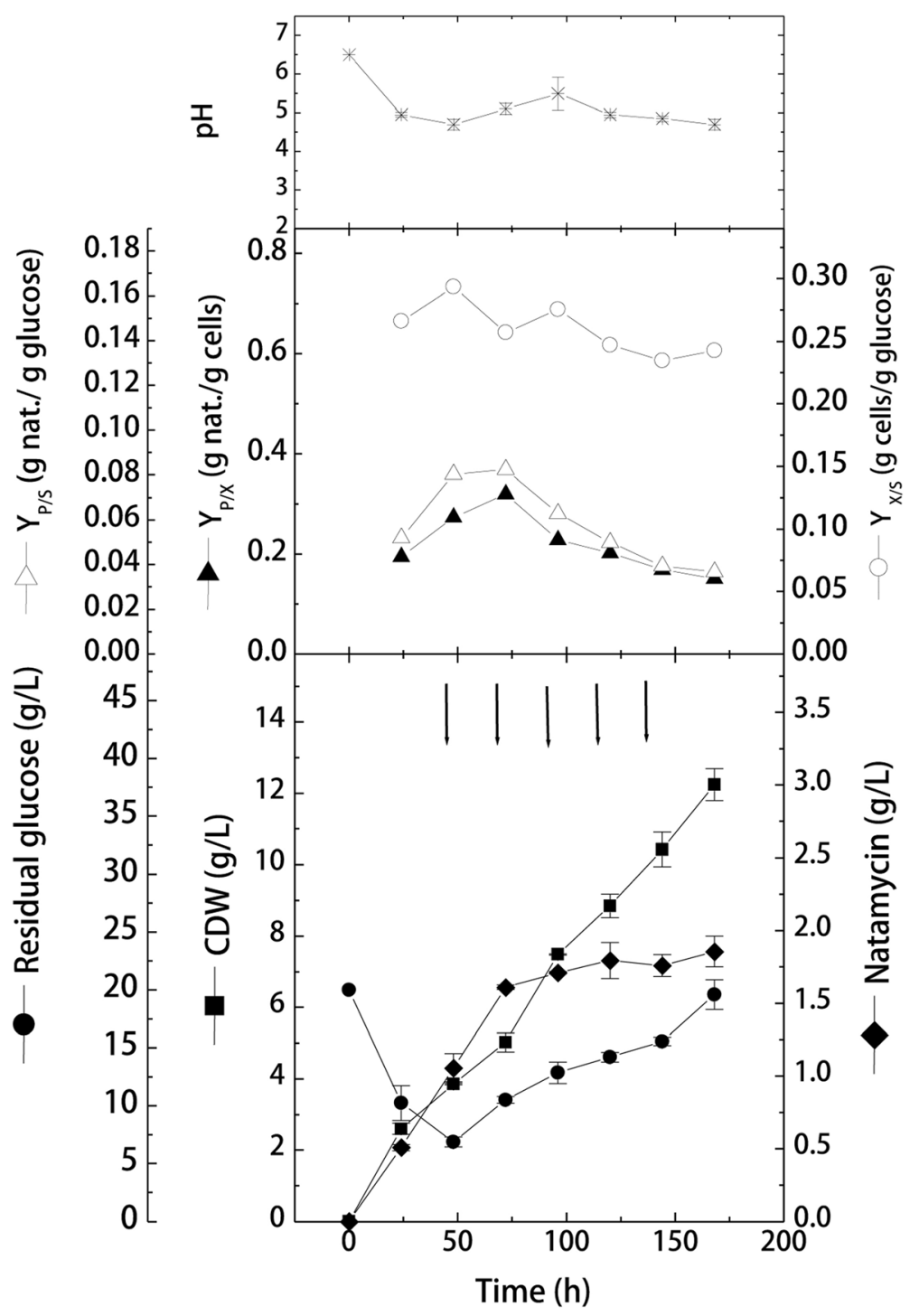

Fig. 3 Effect of intermittent feeding of glucose and beef extract on cell growth and natamycin production by S. natalensis in shake-flask cultivation (CDW, cell dry weight; $Y_{X / S}$ : yield of biomass per consumed glucose; $Y_{P / s}$ : yield of natamycin per consumed glucose; $Y_{P / X}$ : yield of natamycin per biomass)

at 96). Although batch data (Fig. 1) showed that natamycin started to decompose in the production medium after $88 \mathrm{~h}$, and reached a final of $0.913 \pm 0.06 \mathrm{~g} / \mathrm{L}$ by $120 \mathrm{~h}$, however, the intermittent feeding significantly improved natamycin production $(p=0.02)$, where a final concentration of $1.855 \pm$ $0.11 \mathrm{~g} / \mathrm{L}$ was obtained at $168 \mathrm{~h}$.

Yield coefficient results showed that S. natalensis cells continued to produce natamycin after the 1st addition batch with yield coefficients similar to those reported in the batch cultivation $\left(Y_{x / s}, 0.26 \mathrm{~g}\right.$ cells $/ \mathrm{g}$ consumed glucose; $Y_{P / s}, 0.083 \mathrm{~g}$ natamycin/g consumed glucose; $Y_{P / X}, 0.32 \mathrm{~g}$ natamycin/g cells). However, yield coefficients decreased with further addition batches.
Effect of intermittent feeding of glucose on cell growth and natamycin production by $S$. natalensis in shake flasks This part of the work was designed to investigate the effect of intermittent feeding of glucose only on the kinetics of cell growth and natamycin production. The cultivation was performed as previously described, except that the feeding solution contained only glucose at a concentration of $10 \mathrm{~g} / \mathrm{L}$. Results obtained (Fig. 4) showed that, similar to previous batch experiment, cells grew with an average growth rate of $0.085 \mathrm{~g} / \mathrm{L} / \mathrm{h}$ and a glucose consumption rate of $-0.31 \mathrm{~g} / \mathrm{L} / \mathrm{h}$ reaching $4.09 \pm 0.16 \mathrm{~g} / \mathrm{L}$ at $48 \mathrm{~h}$. After starting the intermittent glucose feeding phase, cells continued to grow exponentially for the rest of the cultivation. However, it can be seen that the average growth rate decreased to $0.04 \mathrm{~g} / \mathrm{L} / \mathrm{h}$, which 


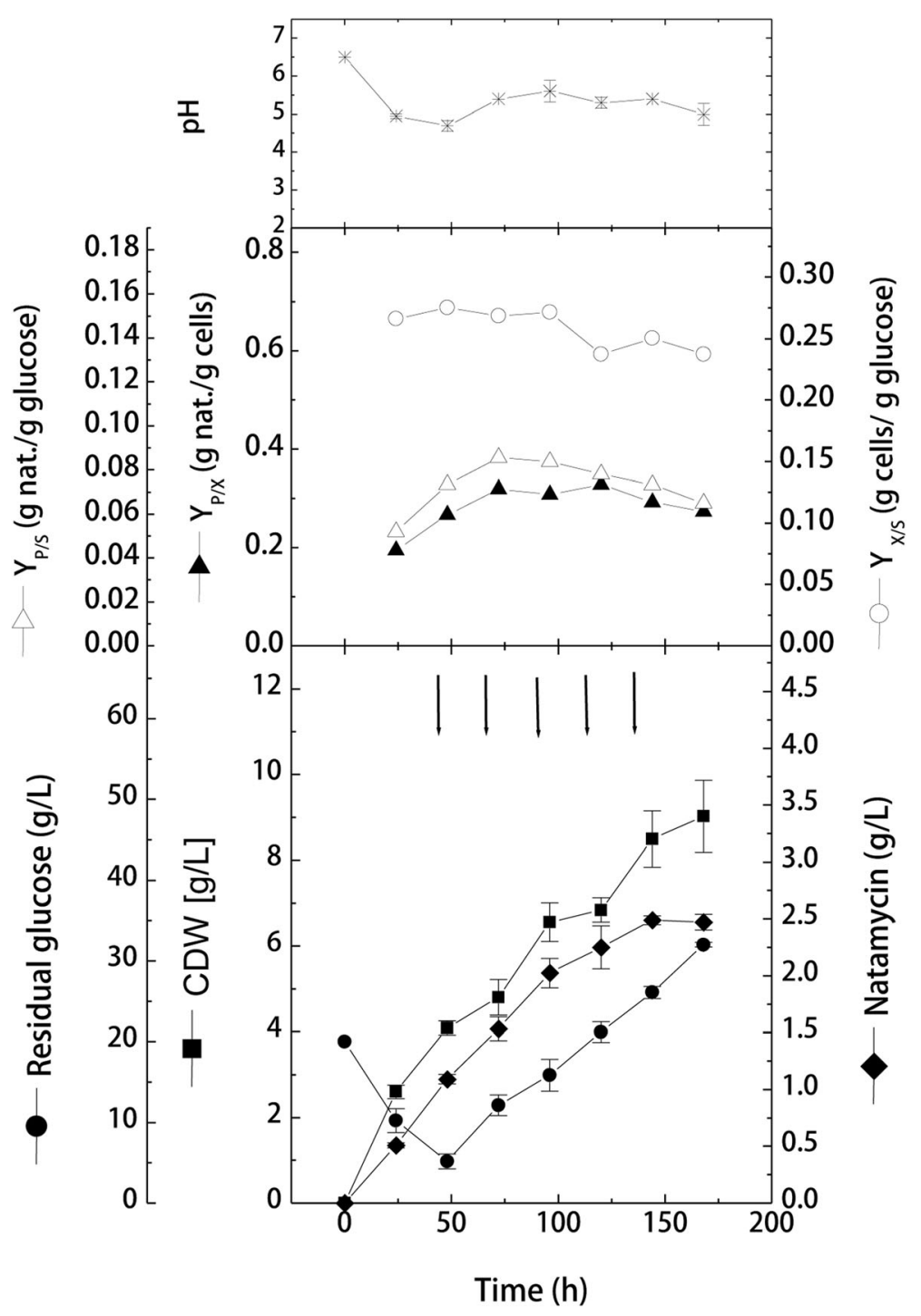

Fig. 4 Effect of intermittent feeding of glucose on cell growth and natamycin production by S. natalensis in shake-flask cultivation (CDW, cell dry weight; $Y_{X / S}$ : yield of biomass per consumed glucose; $Y_{P / S}$ : yield of natamycin per consumed glucose; $Y_{P / X}$ : yield of natamycin per biomass)

is about $42.9 \%$ lower than the average growth rate recorded in case of feeding glucose-beef mixture $(0.07 \mathrm{~g} / \mathrm{L} / \mathrm{h})$. This lower growth rate was reflected on the maximal cell growth obtained by the end of cultivation $(9.03 \pm 0.82 \mathrm{~g} / \mathrm{L})$, which was lower by about $26.3 \%$ from the maximal growth obtained in glucose-beef feeding.

During batch -wise glucose feeding phase, the average glucose consumption decreased from -0.31 to $-0.19 \mathrm{~g} /$ $\mathrm{L} / \mathrm{h}$, which is about $60 \%$ of the average glucose consumption rate obtained during batch-wise glucose-beef feeding $(-0.31 \mathrm{~g} / \mathrm{L} / \mathrm{h})$. This decrease in substrate consumption rate highly increased glucose accumulated in the cultivation flasks, where it recorded $32 \pm 0.29 \mathrm{~g} / \mathrm{L}$ at $168 \mathrm{~h}$, representing about $64 \%$ of the total fed glucose.

Looking at natamycin production kinetics, it can be observed that after the 1st addition batch, natamycin production increased by 1.4-folds recording $1.533 \pm 0.11$ $\mathrm{g} / \mathrm{L}$, and then increased with each glucose addition until reaching a maximal of $2.49 \pm 0.04 \mathrm{~g} / \mathrm{L}$ at $144 \mathrm{~h}$. Additionally, it can be seen that after the 1st glucose addition, natamycin production increased by about $18,25.7,41.5$ and $33.3 \%$ after the 2 nd, 3rd, 4th and 5 th addition, respectively, than those concentrations obtained after the corresponding glucose-beef additions. It is further worth to mention that the maximal produced natamycin in this experiment $(2.49 \pm 0.04 \mathrm{~g} / \mathrm{L})$ was 1.57 -folds higher that the maximal concentration obtained in normal shake flask batch $(1.58 \pm 0.03 \mathrm{~g} / \mathrm{L})$. Yield coefficient results showed that $Y_{P / s}$ was slightly improved from 0.083 to $0.086 \mathrm{~g}$ natamycin/g consumed glucose for glucose-beef and glucose addition, respectively, suggesting that more glucose was converted into natamycin. 
Cell growth and natamycin production 7.5 L-stirred tank bioreactor under batch cultivation mode

This part of the work aimed at investigating the effect of transferring natamycin production process from shakeflask level into stirred tank bioreactor level. S. natalensis cells were inoculated into $7.5 \mathrm{~L}$-stirred tank bioreactor with $5 \mathrm{~L}$ working volume. The cultivation was firstly performed under batch conditions to monitor cell behavior and production kinetics. Results obtained (Fig. 5) showed that bioreactor cultivation significantly improved kinetics of cell growth and natamycin production in comparison to shake-flask batch cultivation $(p=0.003)$. During the exponential growth phase, cells grew with an average growth rate of $0.111 \mathrm{~g} / \mathrm{L} / \mathrm{h}$, and reached $6.3 \pm 0.04 \mathrm{~g} / \mathrm{L}$ of cell growth. Although cells grew almost with the same growth rate recorded in shake-flask cultivation $(0.099 \mathrm{~g} / \mathrm{L} / \mathrm{h})$, however, in bioreactor cultivation, the exponential growth phase was extended to $56 \mathrm{~h}$ ( $14 \mathrm{~h}$ longer than that in shake-flask) before entering the stationary phase. This longer active growth was reflected on the higher cell concentration obtained before the onset of the stationary phase (1.97-folds higher than cell concentration in shake-flask culture). The dissolved oxygen (DO) concentration started to decrease sharply with time up to $20 \mathrm{~h}$, at an average DO consumption rate of $-2.5 \% / \mathrm{h}$. After $20 \mathrm{~h}$, DO concentration remained more or less constant until the end of cultivation, meaning that dissolved oxygen was not limiting. A final cell growth of $6.46 \pm 0.04 \mathrm{~g} / \mathrm{L}$ was obtained at $103 \mathrm{~h}$.

Furthermore, in bioreactor cultivation, the average glucose consumption rate increase by about $23 \%(-0.443 \mathrm{~g} / \mathrm{L} / \mathrm{h})$ than that recorded in shake-flask cultivation $(-0.36 \mathrm{~g} / \mathrm{L} / \mathrm{h})$. Such higher consumption rate can also be seen from the highest yield coefficient $\left(Y_{x / s}\right)$, which recorded $0.73 \mathrm{~g}$ cells $/ \mathrm{g}$

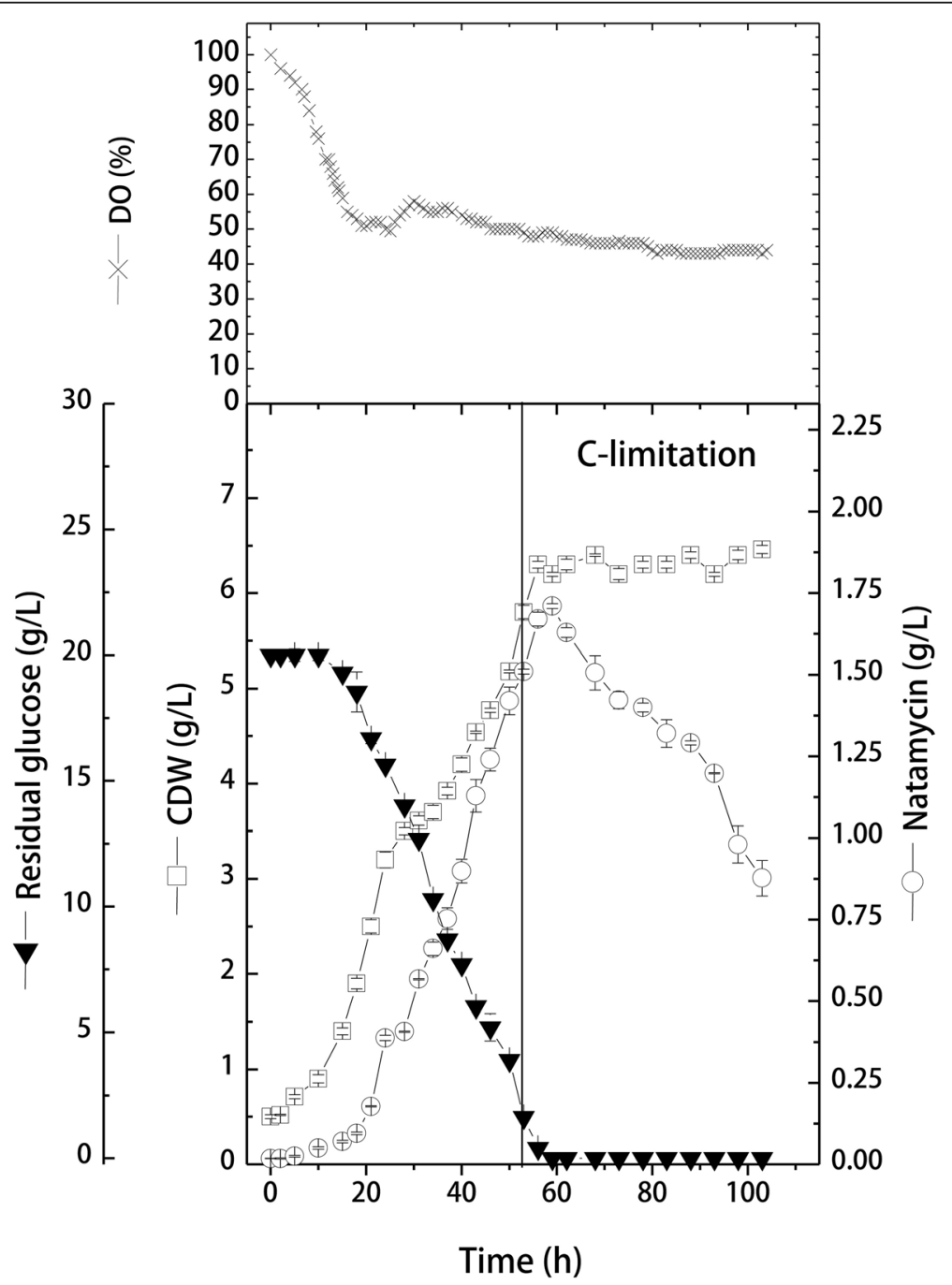

Fig. 5 Cell growth and natamycin production by S. natalensis in 7.5 L-stirred tank bioreactor under batch cultivation mode (CDW, cell dry weight; $\mathrm{DO}$, dissolved oxygen) 
consumed glucose $(0.28 \mathrm{~g}$ cells $/ \mathrm{g}$ consumed glucose in shake-flask cultivation).

Natamycin was produced during the stationary growth phase with an average production rate of $0.038 \mathrm{~g} / \mathrm{L} / \mathrm{h}, 1.8$ folds higher than that recorded in shake-flask cultivation. Consequently, a maximal natamycin production of $1.71 \pm$ $0.01 \mathrm{~g} / \mathrm{L}$ was obtained after $59 \mathrm{~h}$. However, similar to shake-flask cultivation, it can be seen that natamycin degradation started directly after glucose depletion $(60 \mathrm{~h})$, while in shake-flask cultivation, degradation started after $80 \mathrm{~h}$. Also, in both cultivations, the natamycin degradation rates were similar $(-0.014$ and $-0.019 \mathrm{~g} / \mathrm{L} / \mathrm{h}$ for shakeflask and bioreactor cultivations, respectively).

\section{Kinetics of cell growth, glucose consumption and} natamycin production by $S$. natalensis during fed-batch cultivation in $\mathbf{7 . 5} \mathrm{L}$-stirred tank bioreactor

The fed-batch bioreactor cultivation was designed to investigate the effect of continuous glucose feeding on the kinetics of cell growth and natamycin production in order to overcome the problems of glucose limitation. After inoculation, the cultivation was run as normal batch for the first $50 \mathrm{~h}$. Based on the glucose consumption rate obtained from the bioreactor batch run ($0.443 \mathrm{~g} / \mathrm{L} / \mathrm{h}$ ), sterile glucose solution was continuously fed to the bioreactor at a feeding rate of $0.5 \mathrm{~g} / \mathrm{L} / \mathrm{h}$. Feeding was started shortly before glucose becomes limited (at $3.8 \mathrm{~g} / \mathrm{L}$ ), and this phase lasted for the next $30 \mathrm{~h}$. After
$80 \mathrm{~h}$, feeding was stopped and the cultivation mode was turned again into batch mode. Results (Fig. 6) showed that the first batch session proceeded as normal batch where cells reached $5.12 \pm 0.04 \mathrm{~g} / \mathrm{L}$ with a natamycin production of $1.4 \pm 0.035 \mathrm{~g} / \mathrm{L}$. During this phase, growth and production kinetic parameters were similar to a great extent to those obtained in the previous batch cultivation.

Upon feeding glucose to the production medium, cells continued to grow exponentially for the first $14 \mathrm{~h}$ of feeding with a similar growth rate $(0.103 \mathrm{~g} / \mathrm{L} / \mathrm{h})$, and reached their maximal growth of $6.21 \pm 0.05 \mathrm{~g} / \mathrm{L}$ at $64 \mathrm{~h}$. Afterwards, cell growth entered the stationary phase, and remained more or less constant. During the feeding phase, glucose consumption remained constant, where no accumulation was observed and the average available glucose concentration ranged from $4.0 \pm 0.07$ to $4.4 \pm 0.04 \mathrm{~g} / \mathrm{L}$. Therefore, natamycin production continued during the feeding phase, where the average production rate increased up to $0.04 \mathrm{~g} / \mathrm{L} / \mathrm{h}$ (34.5 and $95.7 \%$ higher than the production rate in bioreactor and shake-flask batch cultivations, respectively). Consequently, natamycin production reached $2.52 \pm 0.07 \mathrm{~g} / \mathrm{L}$ by the end of the feeding phase, and continued to be produced during the second batch phase (at a smaller production rate), where a maximal production of $2.72 \pm 0.01 \mathrm{~g} / \mathrm{L}$ was obtained at $103 \mathrm{~h}$. It can be seen that feeding increased maximal natamycin by 1.6 - and 1.72-folds from the maximal production

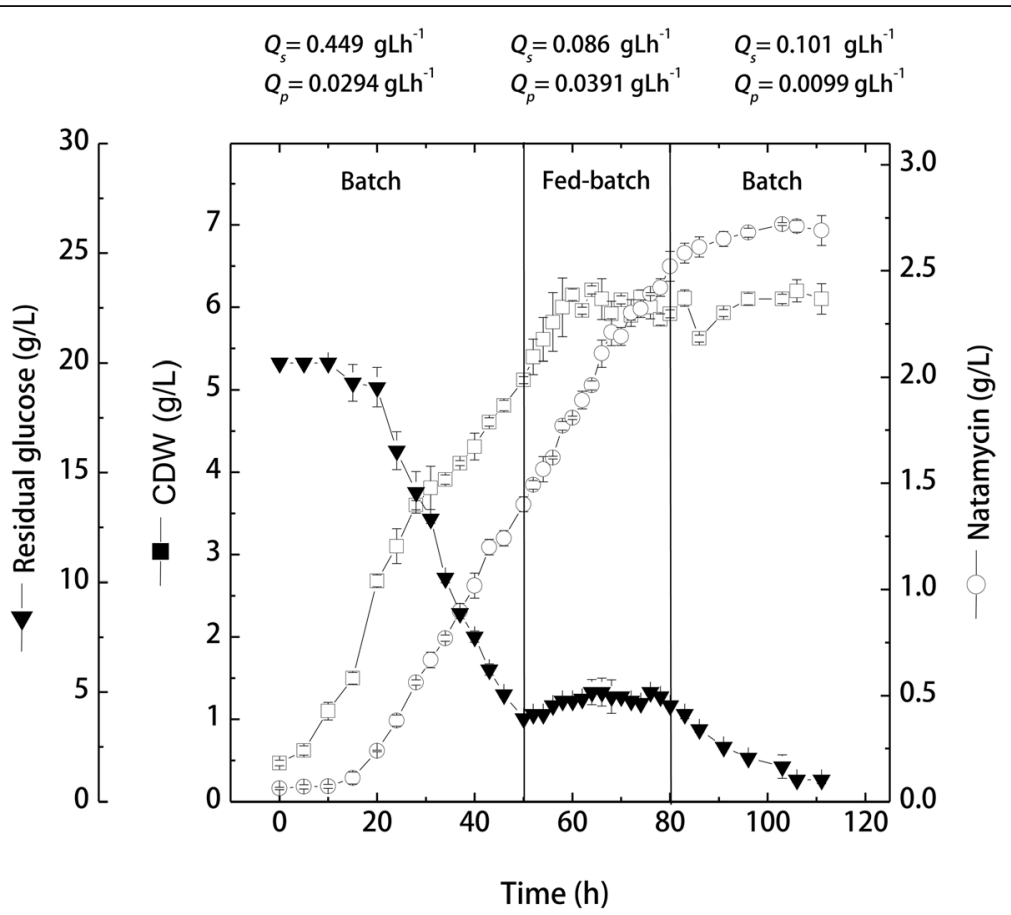

Fig. 6 Kinetics of cell growth, glucose consumption and natamycin production by S. natalensis during fed-batch cultivation in $7.5 \mathrm{~L}$-stirred tank bioreactor (CDW, cell dry weight) 
obtained in bioreactor and shake-flask batch cultivations, respectively.

The production yield coefficients in terms of consumed glucose and producing cells $\left(Y_{p / s}, Y_{p / x}\right)$ were significantly improved in response to continuous glucose feeding. The $Y_{p / x}$ increased from $0.28 \mathrm{~g}$ natamycin/g cells (at $50 \mathrm{~h}$ ) reaching a maximal of $0.42 \mathrm{~g} / \mathrm{g}$ by $80 \mathrm{~h}$, and increased further during the 2nd batch phase to reach $0.47 \mathrm{~g} / \mathrm{g}$ at $86 \mathrm{~h}$. Similarly, $Y_{p / s}$ increased from $0.09 \mathrm{~g}$ natamycin/g consumed glucose reaching its maximal at $80 \mathrm{~h}(0.16 \mathrm{~g} / \mathrm{g}, 2$-folds the yield before feeding).

Finally, Table 2 summarized different kinetic parameters obtained for cell growth and natamycin production under different cultivation conditions. It can be seen that the final cultivation in bioreactor under glucose feeding conditions significantly $(p=0.003)$ improved process parameters in terms of cell growth, substrate consumption, and natamycin production kinetics.

\section{Discussion}

Obtained results showed that glucose concentration has a pronounced effect on natamycin production by $S$. natalensis. Increasing glucose concentration up to $20 \mathrm{~g} / \mathrm{L}$ increased natamycin production, and further increase in its concentration had remarkably decreased the concentration of natamycin. Furthermore, cell growth kinetics, glucose consumption and natamycin production rates, as well as yield coefficients, showed their maximal values at $20 \mathrm{~g} / \mathrm{L}$. These results are in accordance with those previously reported $[5,15]$, where highest natamycin concentration were obtained at lower glucose concentrations. Additionally, higher glucose concentrations showed higher cell growth levels. This can be explained on the basis of carbon catabolite repression and feedback regulation of higher glucose concentrations. Generally, actinomycetes respond negatively towards higher concentrations of glucose and similar low molecular readily metabolizable carbon sources [25]. Higher glucose concentrations usually stimulate higher growth and retarded the production of secondary metabolites. It has been reported that readily utilizable sugars repress or inhibit the enzymatic machinery responsible for the biosynthesis of many antibiotics, e.g. puromycin, kanamycin, penicillin and cephalosporin [27, 28].

Recently, it has been postulated that carbon catabolite repression regulates glucose metabolism by the phosphoenolpyruvate-dependent phospotransferase system affecting glucose kinase (Glk), which acts only on glucose and converts it into glucose-6-phosphate [25, 29]. It has been found that unknown glucose metabolites activate Glk, and that there is an unknown regulatory factor that binds to Glk and changes its function from catabolic one into regulatory one, leading finally to carbon catabolite repression phenomenon [30].

Furthermore, our results showed that natamycin concentrations decreased in $10-20 \mathrm{~g} / \mathrm{L}$ glucose cultivations, while cultivations at higher glucose concentrations did not show such decrease in the volumetric natamycin production. This can be attributed to the cleavage of natamycin molecule by growing cells, present under glucose limitation or depletion, resulting in the release of glucose moiety from the macrolactone ring, and making it available for cells as maintenance energy [5, 15]. Similar results were reported on the decrease in natamycin concentration after reaching its maximal production $[2$, 18]. However, in both cases, the decrease in production was not attributed to natamycin hydrolysis, since the cultivation media contained other slowly metabolized carbon sources. Our results are also in good agreement with those reported by Marin and McDaniel [31], who suggested the same explanation for the decrease obtained in their production of candicidin after $70 \mathrm{~h}$, when glucose was depleted from the medium. Additionally, it has been reported that amphotericin B has been used as

Table 2 Summarized kinetic parameters of cell growth and natamycin production by S. natalensis NRRL 2651 under different cultivation conditions applied

\begin{tabular}{|c|c|c|c|c|c|}
\hline \multirow[t]{3}{*}{ Parameter } & \multicolumn{5}{|c|}{ Cultivation conditions } \\
\hline & \multicolumn{3}{|c|}{ Shake-flask cultivation } & \multicolumn{2}{|c|}{ Bioreactor cultivation } \\
\hline & Batch $(20 \mathrm{~g} / \mathrm{L})$ & Intermittent feeding (glucose+beef) & Intermittent feeding (glucose) & Batch $(20 \mathrm{~g} / \mathrm{L})$ & Glucose feeding \\
\hline$X_{\max }(g / L)$ & $4.780 \pm 0.13$ & $12.25 \pm 0.45$ & $9.030 \pm 0.84$ & $6.460 \pm 0.04$ & $6.21 \pm 0.05$ \\
\hline$P_{\max }(g / L)$ & $1.580 \pm 0.03$ & $1.855 \pm 0.1$ & $2.480 \pm 0.04$ & $1.710 \pm 0.01$ & $2.72 \pm 0.01$ \\
\hline$Q_{x}{ }^{a}(g / L / h)$ & 0.099 & 0.080 & 0.085 & 0.111 & $0.103^{b}$ \\
\hline $\mathrm{Q}_{p}{ }^{a}(g / L / h)$ & 0.021 & 0.022 & 0.023 & 0.038 & $0.045^{b}$ \\
\hline $\mathrm{Q}_{s}{ }^{a}(\mathrm{~g} / \mathrm{L} / \mathrm{h})$ & -0.41 & -0.31 & -0.220 & -0.443 & -0.448 \\
\hline$Y_{x / s}(g / g)$ & 0.280 & 0.260 & 0.280 & 0.760 & 0.61 \\
\hline$Y_{p / s}(g / g)$ & 0.083 & 0.083 & 0.086 & 0.090 & 0.162 \\
\hline$Y_{p / x}(g / g)$ & 0.332 & 0.320 & 0.330 & 0.280 & 0.46 \\
\hline
\end{tabular}

Xmax: maximal cell dry weight; Pmax: maximal natamycin production; QX: average cell growth rate; QP: average natamycin production rate; QS: average glucose consumption rate; YX/S: maximal yield of biomass per consumed glucose; YP/S: maximal yield of natamycin per consumed glucose; YP/X: maximal yield of natamycin per biomass. a Data are calculated at the end of the exponential growth phase. $b$ Data are taken during the feeding phase 
an endogenous substrate by the producing cells [32]. In such case, the produced antibiotic was transformed into the inactive form. The same authors found non-active forms of polifungin and candihexin lacking mycosamine moiety in the fermentation broth following glucose depletion, suggesting the degradation or modification of such antibiotics by the producing cells.

Another possible explanation for the decrease in natamycin concentration at higher glucose concentrations $(30-50 \mathrm{~g} / \mathrm{L})$, is the fast glucose metabolism and the production of organic acids, which in turn decrease the $\mathrm{pH}$ of the medium. It is well known that $\mathrm{pH}$ shift towards acidic values results in the cleavage of aminosugar moiety of mycosamine and its release from the natamycin molecule [33]. Moreover, the propensity to autolysis is a well-known property of different actinomycetes in prolonged cultivations. This has been attributed to $\mathrm{C}$-source depletion, which activates certain molecular mechanism, i.e. proteolytic cascades and nucleases, which in turn results in decreased cell proliferation, differentiation and cell death [34-36].

To overcome the carbon catabolite repression in actinomycetes, it is recommended to perform glucose cultivations with slow feeding of carbon source. Therefore, the second part of the work was conducted to investigate the effect of glucose feeding on the kinetics of cell growth and natamycin production. Firstly, intermittent repeated feeding of glucose alone or glucose-beef extract mixture was carried out on shake-flask levels. Results showed that both intermittent feeding strategies improved the production process in comparison to the preliminary batch cultivation. Volumetric natamycin production increased by about 1.3- and 1.57-folds in glucose-beef mixture or glucose feeding, respectively, than the corresponding batch cultivation. This suggests that slow feeding is useful to bypass the carbon catabolite repression regulation in Streptomyces in case of using glucose as a sole carbon source. Slow feeding of glucose allows higher respiration rates during antibiotic production phase (idiophase) as well as higher productivity [32]. Sugar addition has also been used for the increased production of other polyene antibiotics to overcome rapid glucose consumption $[37,38]$.

However, results showed that glucose feeding was superior to the feeding of glucose-beef mixture in terms of natamycin production. Also, cell growth was much higher in case of glucose-beef feeding. This can be accredited to the fact that the addition of beef extract tends to increase the concentration of organic nitrogen in the production medium. This will result in the conversion of the production phase (idiophase) into growth phase (trophophase), where the metabolism is directed towards cell growth and consequently lowered antibiotic production $[28,31]$. This was accompanied by higher glucose consumption in the glucose-beef feeding, and therefore, lower amounts of glucose were accumulated by the end of the cultivation. Periodic addition of nitrogen source with the fed glucose increased growth over candidin production [28, 39]. Furthermore, the increase in cell growth in case of nitrogen source feeding can be due to the increase in phosphate content found in beef extract. Generally, complex nitrogen sources are used for their balanced contents of fatty acids, proteins, cations and low phosphate. However, the accumulation of beef extract in the medium can lead to increased levels of phosphate in the production medium, which in turns inhibits natamycin production. Phosphate effect on the production of antibiotics by streptomycetes is well known and reported $[25,40]$.

The production process was transferred to $7.5 \mathrm{~L}$ stirred tank bioreactor to investigate the possibility of scaling-up the process from shake-flask into semiindustrial bioreactor level. Results showed that maximal natamycin production was reached at the onset of the stationary phase accompanied by complete glucose exhaustion. Additionally, natamycin production increased linearly and proportional to cell growth. Bioreactor cultivation is generally characterized by the presence of more controlled conditions in terms of $\mathrm{pH}$, better oxygenation and mixing due to controlled aeration and agitation. Such conditions provide the growing cells with more adequate conditions promoting better growing environments and allowing maximal metabolic cellular activities $[41,42]$. Our results also showed that oxygen consumption increased sharply for the first $20 \mathrm{~h}$, representing cell growth in trophophase, and then oxygen consumption remained more or less stable for the rest of cultivation. These results are in agreement with those of Wang et al. [17], who reported on the enhancement of natamycin production by genetically manipulated S. gilvosporeus. They reported similar oxygen consumption rates for the first $12-20 \mathrm{~h}$ of cultivation, where the progress of cell growth was at its highest rates.

The batch bioreactor results showed also decreased concentrations of natamycin after glucose depletion from the cultivation medium. Accordingly, continuous feeding of glucose was carried out in bioreactor to investigate the kinetics of cell growth and natamycin production under these optimized conditions. Results showed that continuous glucose feeding significantly improved cell growth and natamycin production. Volumetric production increased by 1.6- and 1.72-folds from the concentration obtained in batch cultivations in bioreactor and shakeflasks, respectively. This was accompanied by improved specific production yields based on glucose consumption and growing cells. Also, glucose catabolite repression and product degradation were avoided and cells continue to grow and produce natamycin until the end of the cultivation. Furthermore, substrate consumption and natamycin 
production rates were kept nearly constant during batch and fed-batch phases. Although feeding glucose has not yet been explored for natamycin production, however, previous reports are found for the increased production of other polyene antibiotic using slow glucose feeding [28, 31]. Authors suggested that direct or indirect glucose metabolites are involved in the switch between primary and secondary metabolism. Generally, fed-batch cultivation is the choice for improving antibiotic production processes [21-23]. It is used in the production of secondary metabolites, which strictly require fast metabolizable carbon sources in order to avoid their fast metabolism and the conversion from idiophase into torphophase [37, 38]. Furthermore, Wang et al. [43] reported on the production of isovaleryispiramycin under glucose limitation by investigating the effect of different glucose concentrations on the activity of the rate limiting enzyme in the biosynthetic pathway, branched-chain $\alpha$-keto acid dehydrogenase (BCKDH). They found that glucose depletion in the late production phase significantly decreased the activity of the $\mathrm{BCKDH}$ and consequently isovaleryispiramycin concentration. They suggested glucose feeding during this phase to keep glucose levels between 0.0 and $1.0 \mathrm{~g} / \mathrm{L}$, which significantly improved enzyme activity and hence, isovaleryispiramycin production.

\section{Conclusions}

From the aforementioned results, it can be inferred that initial glucose concentration significantly affects natamycin production through activation or inhibition of carbon catabolite repression mechanism. Slow glucose feeding was found to support better natamycin production and prevents the degradation of the product due to glucose limitation. Furthermore, the addition of glucose and beef extract shifted the glucose metabolism and the cultivation from the idiophase into the trophophase, favoring cell growth and retarding natamycin production. Finally, $7.5 \mathrm{~L}$-stirred tank bioreactor was used to optimize the fed-batch cultivation for natamycin production. Such fed-batch resulted in the production of $2.72 \pm$ $0.01 \mathrm{~g} / \mathrm{L}$ of natamycin after $103 \mathrm{~h}$, which corresponds to an increase of about 1.6- and 1.72-folds from the maximal production obtained in bioreactor and shake-flask batch cultivations, respectively.

\section{Methods}

\section{Microorganism and inoculum preparation}

Streptomyces natalensis (NRRL 2651) obtained from the National Center for Agricultural Utilization Research (NRRL, Peoria, Illinios, USA), was used throughout this work. Inoculum in the form of spores obtained from a densely sporulated culture grown on ISP agar medium for 7 days at $30^{\circ} \mathrm{C}$ was used [5]. The arisen spores were harvested with a sterile physiological saline solution $(0.9 \% \mathrm{NaCl}, \mathrm{w} / \mathrm{v})$, and were counted directly using a haemocytometer slide. The natamycin production medium was inoculated with spore suspension at a final concentration of $1 \times 10^{7}$ spores $/ \mathrm{mL}$.

\section{Cultivation media}

ISP agar medium [16], used for sporulation, was composed of $(\mathrm{g} / \mathrm{L})$ as follows: Malt extract (Difco), 10.0; Glucose (BDH), 4.0; and Yeast extract (Difco), 4.0. The final $\mathrm{pH}$ was adjusted to 7.2 before sterilization. Unless otherwise stated, natamycin production medium was composed as follows ( $\mathrm{g} /$ L): Glucose (Difco), 20.0; Yeast extract (Difco), 2.0; Beef extract (Difco), 8.0 and DL-Asparagine (Fluka), 0.5. The final $\mathrm{pH}$ was adjusted to 7.2 before sterilization. Glucose was sterilized separately and added to the medium directly before inoculation. Cultivations were carried out using Erlenmeyer flasks with a total volume of $250 \mathrm{~mL}$ containing $50 \mathrm{~mL}$ medium. The flasks were cultivated on a rotary shaking incubator at $30^{\circ} \mathrm{C}$ and $200 \mathrm{rpm}$ (New Brunswick Scientific Co., Edison, New Jersey, USA).

\section{Bioreactor cultivation}

Submerged cultivations were carried out in a $7.5 \mathrm{~L}$ stirred tank bioreactor Microferm (MF-107, New Brunswick Scientific Co., New Brunswick, NJ, USA) with a working volume of $5 \mathrm{~L}$. Sterilization was carried out at $121^{\circ} \mathrm{C}$ for $30 \mathrm{~min}$. and the separately sterilized glucose was added after cooling. The bioreactor vessel was inoculated as previously described [15], and agitation was performed using a three 4-bladed rushton turbine impellers $\left(d_{i \text { (impeller diameter })}=48 \mathrm{~mm} ; d_{t(\text { tank diameter })}=143 \mathrm{~mm}\right.$, $\left.d_{i} d_{t}^{-1}=0.34\right)$ at $600 \mathrm{rpm}$. Aeration was performed by filtered sterile air $(1 \mathrm{v} / \mathrm{v} / \mathrm{m})$. Dissolved oxygen concentrations were analyzed by polarographic electrode (Ingold, Germany). The $\mathrm{pH}$ was adjusted to 7.2 by the addition of $2.5 \mathrm{M} \mathrm{NaOH}$ and controlled during the cultivation. Foam was suppressed, when necessary, by the addition of silicon antifoam reagent (Fluka, Switzerland).

\section{Feeding cultivations on shake-flask and bioreactor levels}

This section was designed to evaluate the effect of feeding glucose (or glucose + beef extract) on the kinetics of cell growth and natamycin production by $S$. natalensis NRRL 2651. In shake-flask cultures, after inoculation and cell growth for $48 \mathrm{~h}, 5 \mathrm{~mL}$ of sterilized feeding solution $(10 \mathrm{~g} / \mathrm{L}$ glucose, or $10 \mathrm{~g} / \mathrm{L}$ glucose $+4 \mathrm{~g} / \mathrm{L}$ beef extract) were added to the growing cells under aseptic conditions. The feeding solution of glucose and beef extract was prepared at the same $\mathrm{C}: \mathrm{N}$ ratio in the initial cultivation medium. Intermittent feeding was repeated every $24 \mathrm{~h}$ for 5 batches. At the end of each addition run, representative samples (2 flasks) were withdrawn and necessary analyses were performed. In case of bioreactor cultivations, cells were allowed to grow in a batch mode for $50 \mathrm{~h}$, and then sterilized glucose solution 
was continuously fed at a feeding rate of $0.5 \mathrm{~g} / \mathrm{L} / \mathrm{h}$ (depending on the rate of glucose consumption calculated form the bioreactor batch experiments). Continuous glucose feeding was conducted for $30 \mathrm{~h}$, and then the bioreactor cultivation mode was switched again to normal batch mode. Samples were taken and assayed at regular intervals.

\section{Analyses \\ Sample preparation}

During cultivation progress, samples were periodically withdrawn (a: shake flasks: 3 flasks, each $50 \mathrm{~mL}$ broth, or b: bioreactor: $10 \mathrm{~mL}$ broth). The volume of the samples was determined using pre-weighed sterile Falcon centrifuge tubes (BD Biosciences, Franklin Lakes, NJ, USA), and samples were then centrifuged at $5000 \mathrm{rpm}$ for $20 \mathrm{~min}$. A small fraction of the supernatant was frozen at $-20^{\circ} \mathrm{C}$ for glucose and natamycin determination.

\section{Determination of cell dry weight}

The remaining pelleted cells in the Falcon tubes were washed thoroughly using saline solution, and were then centrifuged again. The final supernatant was discarded and the cell pellet was allowed to dry overnight at $80^{\circ} \mathrm{C}$ until a constant weight was reached [44]. The final obtained cell dry weight was expressed as $\mathrm{g} / \mathrm{L}$.

\section{Determination of natamycin concentration}

The determination of natamycin concentration in the fermentation broth was carried out by two methods. Firstly, the fermentation broth was assayed biologically by standard agar plate diffusion method using Saccharomyces cerevisiae as the test organism [5]. Aliquots of the cultivation broth were loaded into wells bored in agar plates, which were previously seeded with the test organism at standard assay conditions. Plates were incubated at $30^{\circ} \mathrm{C}$. The diameters of the inhibition zones were recorded after $24 \mathrm{~h}$. A biological standard curve was drawn between the logarithms of different concentrations of standard natamycin (Gist-Brocades, Delft, Netherlands) and the inhibition zone.

For confirmation, natamycin concentrations were determined using HPLC (Agilent 1200, Agilent Technologies, USA) as described in Wang et al. [17]. The HPLC system was equipped with a UV detector $(303 \mathrm{~nm})$ and a Zorbax Eclipse C18 column. The mobile phase contained $\mathrm{NH}_{4} \mathrm{Cl}$ : acetonitrile: tetrahydrofuran $(75: 20: 5)$ and it was run at a flow rate of $0.5 \mathrm{~mL} / \mathrm{min}$. A standard natamycin (Gist-Brocades, Delft, Netherlands) calibration curve was used to determine natamycin concentration.

\section{Determination of glucose concentration}

The concentration of residual glucose in the medium was detected spectrophotometrically. A glucose enzyme determination kit (Biocon Diagnostik GmbH, Burbach, Germany) was used.

\section{Calculation of kinetic parametrs}

$$
\mathrm{Q}_{\mathrm{x}} \text { Cell growth rate }(\mathrm{g} / \mathrm{L} / \mathrm{h})=\frac{X_{2}-X_{1}}{t_{2}-t_{1}}
$$

where $X_{2}$ and $X_{1}$ are cell mass concentrations at time $t_{2}$ and $t_{1}$, respectively.

$$
\begin{aligned}
& \mathrm{Q}_{\mathrm{s}} \text {, Glucose consumption rate }(\mathrm{g} / \mathrm{L} / \mathrm{h}) \\
& =\frac{C_{2}-C_{1}}{t_{2}-t_{1}}
\end{aligned}
$$

where $C_{2}$ and $C_{1}$ are glucose concentrations at time $t_{2}$ and $t_{1}$, respectively.

$$
\begin{aligned}
& \mathrm{Q}_{\mathrm{P}}, \text { Natamycin production/degradation rate }(\mathrm{g} / \mathrm{L} / \mathrm{h}) \\
& \quad=\frac{P_{2}-P_{1}}{t_{2}-t_{1}}
\end{aligned}
$$

where $P_{2}$ and $P_{1}$ are natamycin concentrations at time $t_{2}$ and $t_{1}$, respectively.

\section{Statistical analysis and result reproducibility}

Experiments were repeated thrice to ensure result reproducibility. In case of shake flask cultures, three flasks were simultaneously withdrawn at the same interval, and their contents were assayed separately. Results were analyzed using SPSS 9.0 , and were expressed as mean \pm SD for three replicates. ANOVA one-way analyses were used to analyze results, and statistical significance was defined as $p<0.05$.

Abbreviations

ANOVA: Analysis of variance

Acknowledgments

Not Applicable.

Authors' contributions

EAE, MAF and HAE proposed the research concept and designed the experiments. They provided necessary tools for experiments, experimental instructions, analyzed and interpreted the data and wrote the manuscript. EAE and HAE carried out the experimental work. All authors read and approved the final manuscript.

\section{Funding}

This work was funded by the Deanship of Scientific Research, King Saud University through Vice Deanship of Scientific Research Chairs. Funding was obtained based on the proposed study and the funding bodies had no further role in data collection, analysis, interpretation or manuscript preparation.

Availability of data and materials

All the data generated in this current work are included in the 'Result and Discussion'.

Ethics approval and consent to participate Not applicable.

Consent for publication

Not applicable.

Competing interests

The authors declare that they have no competing interests. 


\section{Author details}

${ }^{1}$ Bioproducts Research Chair, Zoology Department, Faculty of Science, King Saud University, 11451 Riyadh, Kingdom of Saudi Arabia. ${ }^{2}$ Chemistry of Natural and Microbial Products Department, National Research Centre, Dokki, Cairo, Egypt. ${ }^{3}$ Institute of Bioproduct Development (IBD), Universiti Teknologi Malaysia (UTM), 81130 UTM Skudai, Malaysia. ${ }^{4}$ City of Scientific Research and Technology Application, New Burg Al Arab, Alexandria, Egypt.

Received: 12 March 2019 Accepted: 11 July 2019

Published online: 16 July 2019

\section{References}

1. Aparicio JF, Barreales EG, Payero TD, Vicente CM, de Pedro A, Santos-Aberturas J. Biotechnological production and application of the antibiotic pimaricin: biosynthesis and its regulation. Appl Microbiol Biotechnol. 2016;100:67-78.

2. Zeng Z, Miao W, Zeng H, Zhao K, Zhou Y, Zhang J, Zhao Q, Tursun D, Xu D, Li F. Production of natamycin by Streptomyces gilvosporeus Z28 through solid-state fermentation using agro-industrial residues. Bioresour Technol. 2019;273:377-85.

3. Liu SP, Yuan PH, Wang YY, Liu XF, Zhou ZX, Bu QT, Yu P, Jiang H, Li YQ. Generation of the natamycin analogs by gene engineering of natamycin biosynthetic genes in Streptomyces chattanoogensis L10. Microbiol Res. 2015;173:25-33.

4. Martín JF, Aparicio JF. Enzymology of the polyenes pimaricin and candicidin biosynthesis. Methods Enzymol. 2009;459:215-42.

5. Elsayed EA, Farid MA, El-Enshasy HA. Improvement in natamycin production by Streptomyces natalensis with the addition of short-chain carboxylic acids. Process Biochem. 2013;48:1831-8.

6. Atta HM, El-Sayed AS, El-Desoukey MA, Hassan M, El-Gazar M. Biochemical studies on the Natamycin antibiotic produced by Streptomyces lydicus: fermentation, extraction and biological activities. J Saudi Chem Soc. 2015;19:360-71.

7. Raab W. Pimaricin, ein Antibioticum gegen Pilze und Trichomonaden. Arzneimittelforschung. 1967;17:538-43.

8. Sharma N, Aron N, Agarwal T, Sharma C. Antimicrobial agents for ocular use: bacterial, fungal, viral, and protozoal infections. In: Velpandian T (ed.) Pharmacology of ocular therapeutics, Springer International Publishing, Switzerland, 2016, pp. 285-332.

9. Shulka PK, Singh P, Yadav RK, Pandey S, Bhunia SS. Past, present, and future of antifungal drug development. Top Med Chem. 2018;29:125-68.

10. Hurst WJ, Finley JW, de Man JM. Additives and contaminants. In: deMan JM (ed.) Principles of food chemistry, Springer International Publishing, Switzerland, 2018, pp. 429-474.

11. Wu H, Liu W, Dong D, Li J, Zhang D, Lu C. SInM gene overexpression with different promoters on natamycin production in Streptomyces lydicus A02. J Ind Microbiol Biotechnol. 2014;41:163-72.

12. Kallscheuer N. Engineered microorganisms for the production of food additives approved by the European Union - a systematic analysis. Front Microbiol. 2018:9:1-20 Article ID 1746.

13. Jiang T, Feng L, Zheng $X$, Li J. Physicochemical responses and microbial characteristics of shiitake mushroom (Lentinus edodes) to gum Arabic coating enriched with natamycin during storage. Food Chem. 2013;138:1992-7.

14. Fox PF, McSweeney PLH, Cogan TM, Guinee TP. Microbiology of cheese ripening. Fundamentals of Cheese Science. In: Fox PF, McSweeney PLH, Cogan TM, Guinee TP, editors. Fundamentals of cheese science. New York: Springer; 2017. p. 333-90.

15. Farid MA, El-Enshasy HA, El-Diwany Al, Elsayed EA. Optimization of the cultivation medium for natamycin production by Streptomyces natalensis. J Basic Microbiol. 2000;40:157-66.

16. El-Enshasy HA, Farid MA, Elsayed EA. Influence of inoculum type and cultivation conditions on natamycin production by Streptomyces natalensis. J Basic Microbiol. 2000;40:333-42.

17. Wang S, Liu F, Hou Z, Zong G, Zhu X, Ling P. Enhancement of natamycin production on Streptomyces gilvosporeus by chromosomal integration of the Vitreoscilla hemoglobin gene (vgb). World J Microbiol Biotechnol. 2014;30:1369-76.

18. Ge J, Wang C, Huang S, Du R, Liu K, Song G, Ping W. Biosynthesis regulation of natamycin production from Streptomyces natalensis HDMNTE-01 enhanced by response surface methodology. Prep Biochem Biotechnol. 2017:47:939-44.

19. Qi Z, Zhou Y, Kang Q, Jiang C, Zheng J, Bai L. Directed accumulation of less toxic pimaricin derivatives by improving the efficiency of a polyketide synthase dehydratase domain. Appl Microbiol Biotechnol. 2017;101:2427-36.

20. Li M, Chen S, Li J, Ji Z. Propanol addition improves natamycin biosynthesis of Streptomyces natalensis. Appl Biochem Biotechnol. 2014;172:3224-432.
21. Elsayed EA, Omar HG, El-Enshasy HA. Development of fed-batch cultivation strategy for efficient oxytetracycline production by Streptomyces rimosus at semi-industrial scale. Braz Arch Biol Biotechnol. 2015;58:676-85.

22. Omar H, Elsayed EA, Kenawy AA, Wadaan MA, El-Enshasy HA. Effect of cultivation scale and shear stress on cell growth and oxytetracycline production by Streptomyces rimosus in semi-defined medium. J Pure Appl Microbiol. 2014;8:121-8.

23. Boumehira AZ, El-Enshasy HA, Hacène H, Elsayed EA, Aziz R, Park EY. Recent progress on the development of antibiotics from the genus Micromonospora. Biotechnol Bioprocess Eng. 2016;21:199-223.

24. El-Enshasy HA, Beshay UI, El-Diwany Al, Omar HM, El-Kholy AE, El-Najar R. Improvement of rifamycins production by Amycolatopsis mediterranei in batch and fed-batch cultures. Acta Microbiol Polonica. 2003;51:301-13.

25. Wohlleben W, Bera A, Mast Y, Stegmann E. Regulation of secondary metabolites of Actinobacteria. In: Wink J, Mohammadipanah F, Hamedi J (eds.) Biology and biotechnology of Actinobacteria, Springer International Publishing, Switzerland, 2017, pp. 181-232.

26. Drew SW, Demain AL. Effect of primary metabolites on secondary metabolism. Ann Rev Microbiol. 1977;31:343-9.

27. Martin JF, Demain AL. Control of antibiotic biosynthesis. Microbiol Rev. 1980;4:230-51.

28. Martin JF, McDaniel LE. Submerged culture production of the polyene antifungal antibiotics candidin and candihexin. Dev Ind Microbiol. 1974;15:324-37.

29. van Wezel GP, König M, Mahr K, Nothaft H, Thomae AW, Bibb M, Titgemeyer F. A new piece of an old jigsaw: glucose kinase is activated posttranslationally in a glucose transport-dependent manner in Streptomyces coelicolor A3(2). J Mol Microbiol Biotechnol. 2007;12:67-74.

30. Görke B, Stülke J. Carbon catabolite repression in bacteria: many ways to make the most out of nutrients. Nat Rev Microbiol. 2008;6:613-24.

31. Martin JF, McDaniel LE. Kinetics of biosynthesis of polyene macrolide antibiotics in batch culture: cell maturation time. Biotechnol Bioeng. 1975;17:925-38.

32. Martin JF, McDaniel LE. Production of polyene macrolide antibiotics. Adv Appl Microbiol. 1977;21:1-52.

33. Belakhov W, Garabadzhiu AV. Polyene macrolide antibiotics: mechanisms of inactivation, ways of stabilization, and methods of disposal of unusable drugs. Russ J Gen Chem. 2015;85:2985-3001.

34. Filippova SN, Vinogradova KA. Programmed cell death as one of the stages of Streptomycete differentiation. Microbiology. 2017;86:439-54.

35. Farid MA, El-Diwany Al, Daniel EN, El-Enshasy HA. Production of oxytetracycline and lysine using mixed-culture fermentation. Chem Mikrob Technol der Lebensm. 1995;17:139-44.

36. El-Enshasy HA, Farid MA, El-Diwany Al. Oxytetracycline production by free and immobilized cells of Streptomyces rimosus in batch and repeated batch cultures. Prog Biotechnol. 1996;11:437-43.

37. Siewert G, Kieslich K. Preparation and ultraviolet light-induced transformation of an antifungal mixture of heptaene antibiotics of Streptomyces surinam. Appl Microbiol. 1971;21:1007-10.

38. Tereshin IM. Polyene antibiotics: present and future. University of Tokyo Press, Tokyo, Japan. 1970.

39. Gil JA, Liras P, Martin JF. The polyenes: properties, biosynthesis, and fermentation. In: Vandamme EJ, editor. Biotechnology of industrial antibiotics. New York and Basel: Marcel Dekker Inc.; 1984. p. 513-29.

40. Barreiro C, Martinez-Castro M. Regulation of the phosphate metabolism in Streptomyces genus: impact on the secondary metabolites. Appl Microbiol Biotechnol. 2019;103:1643-58.

41. Dailin DJ, Elsayed EA, Othman NZ, Malek R, Phin HS, Aziz R, Wadaan M, El Enshasy HA. Bioprocess development for kefiran production by Lactobacillus kefiranofaciens in semi industrial scale bioreactor. Saudi J Biol Sci. 2016;23:495-502.

42. El-Enshasy HA, Elsayed EA, Suhaimi N, Malek RA, Esawy M. Bioprocess optimization for pectinase production using Aspergillus niger in a submerged cultivation system. BMC Biotechnol. 2018;18:71 https://doi.org/10.1186/s12896-018-0481-7.

43. Wang Y-H, Wu C-H, Chu J, Hao Y-Y, Zhuang Y-P, Zhang S-L. Regulation of branched-chain amino acid catabolism: glucose limitation enhances the component of isovalerylspiramycin for the bitespiramycin production. Bioprocess Biosyst Eng. 2010;33:257-65.

44. Elsayed EA, El-Enshasy HA. Effects of different aeration rates and feeding strategies on cell growth and invertase production kinetics by Saccharomyces boulardii. J Sci Ind Res. 2018;77:575-82.

\section{Publisher's Note}

Springer Nature remains neutral with regard to jurisdictional claims in published maps and institutional affiliations. 